\title{
SALUD
}

\section{Manejo ortodóncico del paciente periodontalmente comprometido y disminuido. relato de caso clínico}

\author{
Walter Solis Melgarejo ${ }^{1}$
}

\begin{abstract}
Resumen
Introducción: El manejo ortodóncico que se debe dar a pacientes con compromiso periodontal ha sido ampliamente debatido a lo largo de los años. Antiguamente se proponían manejos totalmente conservadores y solo los procedimientos quirúrgicos periodontales se tenían en cuenta para devolver algo de la función de los componentes del complejo dentoalveolar que se habían perdido. En la actualidad ha sido posible comprobar cómo el tratamiento ortodóncico en este tipo de pacientes no está contraindicado si siguen unos protocolos de manejo adecuados y paradójicamente la ortodoncia se ha convertido en una opción para solucionar muchas de las secuelas que deja la enfermedad periodontal.
\end{abstract}

Objetivo: El presente trabajo de investigación tiene por objetivo conocer el manejo ortodóncico del paciente periodontalmente comprometido y disminuido. Con el relato de un caso clínico.

Material y Método: Relato de caso clínico. Se presentó en el Instituto Randall en el consultorio del Dr. Diego Defazio, referida por otra colega. Una paciente del sexo femenino de 29 años de raza amarilla (Blumenbach) de etnia china.

Diagnóstico periodontal. 2013 Paciente con antecedente de periodontitis, se encuentra con gran pérdida ósea en zona de anteriores superiores 1.1 y 1.2 también en PM sup. Izq. y 1 ros molares. Se observa clínicamente bolsas periodontales y movilidad patológica grado I en los dientes anteriores sup. y grado II en el 3.4. Valoración de acuerdo a los datos obtenidos, presenta Periodontitis Agresiva.

Diagnóstico ortodóncico. 2014 Paciente con Periodontitis Agresiva Controlada. Diastemas en el sector anterosuperior. Biprotrusión. Clase canina II. Ligero apiñamiento anteroinferior.

Evaluación cefalométrica lateral de Ricketts, Mesofacial en normoclusión.

La aparatología utilizada: Barra transpalatina de anclaje superior del 1.6-2.6. Multibrackets de la técnica M.B.T. slot 0.022", con una biomecánica orientada

\footnotetext{
1 Universidad Autónoma del Paraguay, Facultad de Odontología Pierre Fauchard.

Este trabajo se realizó y defendió para la obtención de la especialización en Ortodoncia en el postgrado de la Facultad de Odontología Pierre Fauchard en el año 2017.

E-mail:waltersolism@yahoo.com.ar

DOI: $10.26885 /$ rcei.foro.2018.132
} 


\section{Manejo ortodóncico del paciente. Solis Melgarejo}

hacia la utilización de fuerzas ligeras, mínimo desplazamiento dentario y menor tiempo de tratamiento, arcos redondos de acero 0.012", 0.014", 0.016", 0.018", $0.020^{\prime \prime}, 0.014^{\prime \prime}$.

Contención removible superior (placa de Hawley), contención fija inferior 3x3 contorneado para facilitar el uso del hilo dental.

Resultados: 2015 El resultado del caso, obtenido a los 18 meses de tratamiento, en cuanto a las relaciones interdentales se logró obtener una clase I canina, corrección del apiñamiento anteroinferior y cierre del diastema anterosuperior. Periodontalmente la respuesta fue positiva, esto se puede corroborar con el sondeo periodontal obtenido un año postratamiento comparado con el referido pretratamiento y la obtención de papila gingival entre 1.2 y 1.1 que antes carecía.

Conclusiones: En éste caso clínico se muestra cómo es posible mejorar las condiciones de arquitectura periodontal y mantener los niveles de salud periodontal logrados después de acertadas terapias mecánicas y antimicrobianas. Además, los cambios muestran cómo las motivaciones estéticas se pueden solucionar con mecánicas simples y poco invasivas.

Palabras clave: Periodontitis Agresiva, biomecánica de ortodoncia, periodoncia y ortodoncia.

\section{Referencias}

Bueno, R., Rodríguez, D. (2010). Tratamiento Interdisciplinario de Periodontitis Agresiva Localizada: Reporte de un Caso. Rev. Clínica de Periodoncia, Implantología y Rehabilitación Oral, 3(2). Recuperado de http://www.sciencedirect.com/ science/article/pii/S0718539110700483

Holmberg, F., Sandoval, P., Holmberg, F. (2008). Movimientos Ortodónticos en Paciente con Soporte Periodontal Disminuido. Rev. Int. J. Odontostomat, 2(1), p. 21-26. Recuperado de http://ijodontostomatology.com/pdf.2(1)/ Mov_Ortodonticos.pdf

Peña Ruiz, T. Martínez Brito, I., Delgado Ramos, A. (2007). Tratamiento integrado ortoperiodontal en la periodontitis juvenil: Presentación de un caso. Rev. Cubana Estomatol, 44(4). Recuperadp de http://scielo.sld.cu/scielo. php?script=sci_arttext\&pid=S0034-75072007000400016\&lng=es

Sada-Garralda, V., Caffesse, R. G. Enfoque ortodóncico en el tratamiento multidisciplinario de pacientes adultos: Su relación con la periodoncia. RCOE, 8(6), p. 673-684. Recuperado de http://scielo.isciii.es/scielo. php?script=sci_arttext\&pid=S1138-123X2003000600006\&lng=es

Velázquez, S., Guzmán, I. (2017). Tratamiento ortodóncico en paciente clase III, periodontalmente comprometida: reporte de un caso. Rev. Mexicana de Ortodoncia, 3(4):274-282. Recuperado de http://www.sciencedirect.com/ science/article/pii/S2395921516300526 